\title{
Understanding the nature of entrepreneurial leadership in the startups across the stages of the startup lifecycle
}

\author{
Nino Dvalidze ${ }^{1}$, Evangelos Markopoulos² \\ ${ }^{1}$ Queen Mary University of London, Mile End Rd, E1 4NS, London United Kingdom, \\ n.dvalidze@hss17.qmul.ac.uk \\ ${ }^{2}$ HULT International Business School, 35 Commercial Road, Whitechapel, E1 1LD, \\ London United Kingdom, evangelos.markopoulos@faculty.hult.edu
}

\begin{abstract}
Start-ups are important part of the world economy. Despite the astonishing rate of the start-up creation, their viability and success remain to be relatively low. Reasons behind the failure are diverse and complex. The leadership has been recognized as an important factor influencing the performance of start-ups. The paper argues that entrepreneurial leadership theory can effectively capture the complex processes in start-ups. The paper explores a broader understanding of the entrepreneurial leadership by examining the context around which the entrepreneurial leadership occurs. Additionally, it includes leader and follower perspective in constructing the phenomenon. Lastly, the research reveals that it is important to view the Entrepreneurial leadership as a process developing along the stages of the start-up life cycle. The findings suggest that leadership is changing across the lifespan of the start-ups and distinct conditions and features are characteristic for the entrepreneurial leadership within each respective stage.
\end{abstract}

Keywords: Entrepreneurial Leadership, Leadership, Entrepreneurship, Start-up, Start-up Life-cycle

\section{$1 \quad$ Introduction}

Start-ups are an important part of the world economy and its growth. The significance of start-ups is obvious in the UK's economy. 2016 data shows that per 10000 populations, only in London, 112.3 start-ups have been reported [1]. Despite the astonishing rate of the start-up creation, the viability and success of start-ups remain to be relatively low [1]. Reasons behind the failure are diverse and complex. Leadership has been long recognized as one of the important factors influencing the performance of start-ups [2].

Some of the mainstream leadership theories, such as Transformational Leadership and Charismatic leadership have been found to have a positive effect on growth and development of start-ups [3].

Entrepreneurial leadership is an emerging theory in the leadership research that is considered to be a more adequate way of understanding the complex leadership processes in the new venture creation and growth. The theory has been developing at 
the intersection of the leadership and entrepreneurship research and is a result of exchanges of ideas and elements between two different academic fields. Until now, entrepreneurial leadership has been examined from these two loops and maintains the scholarly interest of the scholars from both fields [3].

Despite the amount of the studies produced, there is no academic consensus on conceptualizing the entrepreneurial leadership. Additionally, no sufficient measurement tools have been developed for the entrepreneurial leadership [3].

As the phenomenon is still in its infancy, it is important to explore the perceptions and views of the people involved in the entrepreneurship venture. Analyzing the themes and ideas that participants of these processes reveal, will increase the knowledge on the entrepreneurial leadership.

The paper aims to address the research gap in the literature related to the entrepreneurial leadership. In doing so, the study is designed to qualitatively analyze the nature of the entrepreneurial leadership in the selected start-ups in order to enhance the knowledge about what elements are associated with the entrepreneurial leadership and explore the context where the phenomenon occurs.

The significance of the current research needs to be viewed in the following aspects: Firstly, the present research gives more accurate understanding of the elements of the entrepreneurial leadership and outlines the specificities of the context the leadership occurs, by demonstrating personal examples of the respondent entrepreneurs. Secondly, the study offers its examination on whether the various stages of the start-up development affect the leadership processes through analyzing similarities and differences. And finally, the present research examines the leadership processes and relationships from the perspective of the leader and follower, by including both founders and employees of the start-up in the study.

\section{$2 \quad$ Literature Review}

\subsection{Entrepreneurial Leadership}

Entrepreneurial Leadership had been discussed much earlier than the term appeared. Schumpeter was one of the pioneers to connect the entrepreneurship and leadership [4]. Following that Cunningham and Lischeron (1993) have identified a number of characteristics of the entrepreneurial leader such as setting clear goals, creating opportunities, empowering people, preserving organizational intimacy, and developing a human resource system [5].

Despite the amount of the research produced there's no definitional clarity or appropriate tools to assess the entrepreneurial leadership [3]. One of the recent definitions views the Entrepreneurial Leadership as influencing and directing the performance of group members towards the achievement of organizational goals that involve recognizing and utilizing the entrepreneurial opportunities [6]. The present research follows the definition of the Entrepreneurial Leadership by Leitch and Volery (2017) suggesting that Entrepreneurship Leadership means "leadership role performed in entrepreneurial ventures, rather than in the more general sense of an entrepreneurial style of leadership" [3] 
Despite of the certain similarities that the entrepreneurial leadership bears to the mainstream leadership theories, it differs in one important aspect: entrepreneurial leadership emerges in the intersection of the leadership and entrepreneurship and has a significant impact from both research areas. Thus, the entrepreneurial leadership is not considered exclusively from the perspective of leadership, but it is an integration of the leadership as well as the entrepreneurship [3], [6], [7]. Number of scholars argue, that it's a distinct leadership style with unique characteristics that set the theory apart from other leadership theories and requires discrete analysis [3], [6], [8]. Major arguments of the scholars supporting this viewpoint include the fact that entrepreneurial leadership is a merger of Entrepreneurship and Leadership so it cannot be considered from just leadership perspective [3], [6].

Significant recent trend in the entrepreneurial leadership research is shifting from the static, descriptive analysis of the phenomenon to the more dynamic visualization of the nature of entrepreneurial leadership [3].

Entrepreneurial behaviour can be relevant to many different contexts, including large organizations, non-profit, social enterprises, etc. Some academics argue that entrepreneurial leadership is not specific to any context and can be successfully utilized at any type of organization. Yet, the entrepreneurial leadership displays the biggest impact on the new venture creation and more specifically when it is utilized in the startups' settings [6].

\subsection{Entrepreneurial Leadership in Start-up's}

A significant number of academic research have attempted to analyze leadership in the start-ups. Nevertheless, the research has mostly been influenced by the mainstream leadership theories such a transformational leadership, charismatic leadership, etc [9]. The limited research investigates the emerging leadership theories, like entrepreneurial leadership that could be more relevant for understanding the leadership processes in the complex settings of the new ventures [3], [6].

Literature related to the entrepreneurial leadership in the start-ups has linked the concept to the innovation behaviour, as well as innovation and creativity in general. Entrepreneurial leaders are considered to be key drivers of innovation and creativity [10]. According to the study of Huang et al, the entrepreneurial leadership has a significant influence on exploratory and exploitative innovation activities in the organization. The study also highlights the influence of the environmental factors on the innovation processes in the start-ups [11]. Cai et al. (2018) discuss the impact of the entrepreneurial leadership on the creativity in the organizations. Based on the social cognitive theory, researchers analyze the effect of the entrepreneurial leadership on the individual and team creativity. Quantitative analysis of the leaders and employees of the Chinese companies give interesting data on the positive influencing factors of the entrepreneurial leadership on the efficiency of the creativity both on individual and team levels [7].

\subsection{Leadership and the Start-up Life-cycle}

Start-up life and classification of the stages of its development are complex and ambiguous leading to significant controversies in the literature [12], [13], [14]. 
Understanding the leadership processes in light of this ambiguity is even more problematical, however a number of researchers have already attempted to relate and analyze two concepts:

Swiercz and Lydon (2002) investigate the impact of entrepreneurial CEO on a startup development at the different stages of the start-up life-cycle. Researchers argue and provide relevant research findings to prove the importance of the leadership in the startup growth and success. These authors identify two distinct sets of leadership competencies (self-competencies and functional competencies) that are essential for the founders that aspire to remain in the start-up leadership at various stages of the start-up growth. Swiercz and Lydon developed a two-phase entrepreneurial leadership model relevant to the two phases (Formative and Institutional) of the start-up growth [12].

Freeman et al. (2015) discuss challenges that entrepreneurial leaders face on their way from launching the start-up to achieving significant growth of the venture. The researchers conclude that three major leadership challenges linked to the start-up growth process are: developing a vision, achieving optimal persistence, and executing through chaos. Respectively, the authors suggest three important capabilities that address those challenges: strategic thinking, coaching, and self-evaluation [13].

\subsection{Entrepreneurial Leadership Conceptual Framework}

In case of the present paper, we avoid testing any particular theoretical framework but compile the elements of the Entrepreneurial leadership conceptualization suggested by a number of authors such as the opportunity recognition, influential abilities of the leader, etc. [8], [15].

Main theoretical basis of the present research is the construct of entrepreneurial leadership developed by Renko et al., (2013) which includes 8 elements for understanding entrepreneurial leaders. These behavioural characteristics are: (1) Often comes up with radical improvement ideas for the products/services we are selling; (2) Often comes up with ideas of completely new products/services that we could sell; (3) Takes risks; (4) Has creative solutions to problems; (5) Demonstrates passion for his/her work; (6) Has a vision of the future of our business; (7) Challenges and pushes other(s) to act in a more innovative way; (8) Wants me to challenge the current ways we do business. Hence, the researchers suggest the key elements of the entrepreneurial leadership and develop respective measurement tool for testing it in various contexts. By testing the reliability and validity of a tool for the entrepreneurial leadership construct, the researchers argue that the proposed construct is a valid tool as the findings of the research demonstrate the prevalence of entrepreneurial leadership among founder-leaders over non-founder leaders [6]. The concept has been criticized [16], as it mostly shows the follower's perspective and ignores how leaders perceive their abilities. Also, the construct is considered to be following the trait perspective of the leadership and has been criticised as it fails to take into account the impact of context [16].

We address the following criticism by expending the conceptual framework in the following ways:

1 Additional elements relevant to the entrepreneurial leadership will be explored. 
2 In addition to the followers' perspective, the leaders' viewpoint will be included.

3 The contextual factor where each element occurs will be explored.

4 The research also builds on the literature on organizational development and growth and more specifically adopts the model for start-up growth and development introduced by Overall and Wise (2015) to understand the changes in the entrepreneurial leadership process [14].

Hence, the present paper will explore the following research questions: What is the nature of the entrepreneurial leadership in the start-ups? To what extent do the stages of the start-up life cycle affect the entrepreneurial leadership?

\section{$3 \quad$ Methodology}

As the literature review on the Entrepreneurial leadership demonstrated, the phenomenon is still in its infancy and strives to gain the distinct shape in the big picture of the leadership research. For that reason, qualitative research was a strategic choice. Although qualitative research involves smaller samples that might not be sufficient representation of the relevant population, it still allows getting substantial insights of the experiences and perspectives from the standpoint of the representatives of a specific population.

\subsection{Research Philosophy, Method, Data Generation \& Analysis}

The present work follows the Interpretive paradigm as we share the idea that deep meaning of the phenomena can be captured through human thoughts, by uncovering how they are understanding their world [17]. The study explores the themes, patterns, and relationship that peoples reveal when giving the account of their world; so in that sense, using the Grounded Theory is a sufficient methodological strategy [18]. The choice of the Grounded theory can also be justified, as this methodological strategy has been widely used in the leadership research and is suggested as an adequate method for generating the theory [19]. An expected outcome of grounded theory as a methodological strategy in case of the present paper would be advancing the already existing entrepreneurial leadership theory by exploring the themes and drawing generalizable findings from specific examples using the inductive approach.

The semi-structured interviewing method has been chosen for data collection. As the aim of the research is to explore the phenomenon in the real context, semi-structured interviews give a significant amount of flexibility for extensively exploring the perceptions of the research participants around the topic of research [20].

The interview protocol comprises of 3 blocks and was based on the literature on the entrepreneurial leadership. The first part contains general introductory questions aimed at setting the scene and implied some general questions about the start-up and respondent's role in the start-up. The second part includes questions that explore the features and elements as well as the context of the entrepreneurial leadership and the third part explores the entrepreneurial leadership across the start-up life cycle.

10 entrepreneurs were selected for the interview. To identify relevant participants the purposive sampling approach has been used that followed the following criteria and 
representation: gender ( 6 males and 4 female), role in the start-up ( 5 employees and 5 founders), and industry (multiple industries); The average age of the participants was 31 years. The average time of the interview was 30 minutes. Interviews were organized during early July and early August 2018 in Central London. To preserve the anonymity the participants were coded referenced by the respective codes. Interviews were transcribed using the software www.temi.com and have been checked for accuracy by the authors to eliminate any potential errors.

Coding of the data was performed in 2 phases: at first stage, selective coding was used to categorize the data according to the themes that derived from the existing literature. An inductive approach was adopted and open coding used to analyze emerging themes and patterns reoccurring across the interviews [21].

A number of studies have employed semi-structured interviews in the entrepreneurial leadership research [19], although most of them focus only on entrepreneur-founders and do not include the followers' voice in constructing the phenomenon, which is a significant limitation of the studies mentioned above. To overcome this weakness, the present research reported both employers and founders of the start-up companies, several of them being serial entrepreneurs, having diverse experience in various start-ups. Thus, using more than one data source within the present study to examine a phenomenon increases the validity of the findings.

\section{$4 \quad$ Data Findings}

Below we summarize the findings from selective coding, developed based on the literature. Following to that, the findings, that have emerged through adopting open coding, are presented.

\subsection{Understanding Nature of Entrepreneurial Leadership}

Introducing the term entrepreneurial leadership made it clear that none of the participants were familiar with the concept, but all of them were able to elaborate their own understanding of the entrepreneurial leadership. While doing so, the participants focused on various important aspects.

What is Entrepreneurial Leadership? All participants suggested that Entrepreneurial leadership in start-ups is different from the leadership in other settings. When discussing the differences, participants highlighted contextual factors such as uncertain environment, absence of formal structure, limited availability of resources, etc. that would require specific leadership behaviours. Additionally, the participants stressed the attributes and qualities of the founders such as risk-taking, innovative, and passionate that would define entrepreneurial leadership in start-ups.

Why is Entrepreneurial Leadership Important in the Start-up? When defining leadership in the start-ups, both founders and employees agree that leadership is an essential element for the start-up development and growth. When sharing their views on how the leadership is enacted in the start-up both founders and employees suggested that it is essential for the leader to have the necessary knowledge of all aspects of the start-up work and having self-awareness of why he/she is starting a new venture. Interviewees also reveal the factors that lead to the successful entrepreneurial 
leadership, among those they stress the human resource aspect, ability to find the right people and create a sustainable team. Furthermore, participants suggest the importance of the values and ethical conduct that the leader-founder brings into the company.

\subsection{Elements and Features of the Entrepreneurial Leadership}

The research revealed that the major elements that interviews identify with regards to the entrepreneurial leadership are similar to the elements suggested by Renko et al., (2013) and other authors referred to in the literature review section. Participants describe interesting examples related to each element and give important contextual specificities related to each element. Participants of the research suggest that "risk", "passion", "vision" and creativity/Innovation are major elements of the entrepreneurial leadership in start-ups and those elements can be exhibited in various ways.

Risk: Both founders and employees of the start-up believe that risk is associated with every single aspect of the start-up life. 3 out of the 5 founders have quit their job before starting their start-up, which they consider to be the major risk they have taken. Both founders and employees agree that it is important to carefully analyze and be sensible about risks in order to manage and averse those.

Vision: Vision is another essential element of the entrepreneurial leadership according to the participants of the study. They highlight the importance of having a clear vision for the future of the start-up that affects the organizational effectiveness, team spirit and confidence of the actors connected to the start-up.

Passion: Interviewees consider an essential element for the entrepreneurial leaders to have a passion that helps them empower the team, enables leaders to keep motivation during challenging times. Passionate leaders are more successful with raising funds and scaling up the process.

Innovation and creativity: Innovation and creativity have been used as the interchangeable terms and have been considered as one of the key elements of the entrepreneurial leadership. Participants believed that innovativeness has to be considered at every aspect of the start-up leadership, it should be the way the leaders think and act and enable others to perform in a more innovative way. Employees and founders perceptions differ on how the innovation is enacted in the start-up. Start-up leaders think that any employee, including interns, should think and act innovatively. While employees perspective suggests being more cautious about forcing innovation on others within the entrepreneurial teams. Employees also state that it depends on the founder's leadership to materialize and implement innovative ideas that employees are coming up with. Innovation is considered to be the way start-ups deal with the day-today challenges. Specificity of the start-up context demand more innovative, fast solutions and decision-making from all actors involved in the start-up.

\subsection{Entrepreneurial Leadership as a Process}

Participants share the view that entrepreneurial leadership is not a fixed state; quite the reverse, they believe it is a dynamic process of change and is influenced by various factors. Questions were formulated in a way to capture the perceptions and experiences of participants view of Entrepreneurial Leadership across various stages of the start-up growth. Chart demonstrating the four stages of the start-up life cycle [14] has been 
displayed and participants were asked to elaborate on entrepreneurial leadership processes relevant for each stage.

Both the employees and the founders participating in the study differentiate entrepreneurial leadership at 4 exhibited stages of the start-up development and consider various aspects and factors contributing to shaping leadership at every stage of the start-up life. The related findings are summarized below:

Stage 1: Majority of the participants characterize the leadership in the initial stage of the start-up development as "passionate", "courageous", and "resilient". Interviewees believe that these are the leadership traits and behaviours that are essential in order to push forward the innovative idea to transform into a start-up, as well as to cope with the volatile environment.

Stage 2: Participants link this stage with agile and open leadership.

Stage 3: Most of the interviewees share the idea that at this stage leadership focus shifts to building up the right team and sourcing the right talents, one of the interviewees naming it as a "Lean leadership".

Stage 4: Interviewees suggest that at this stage leader should focus on assigning right roles in the team, empowering the people and sharing the leadership responsibilities.

\subsection{Leadership in the Contexts of the Leader-follower Relationship}

The topic of sharing leadership responsibilities among various actors in the start-up as well as shifting leadership roles among the collaborators have emerged as a distinct theme during the interviews. Participants justify the importance of sharing leadership with the specificities of the start-up environment such as a need for a fast decisionmaking, small teams, the absence of the hierarchy and importance of sustaining available human resources.

Key challenges in the leader-follower interaction, that some of the interviewees suggest, is the ego of the leaders and desire to retain own power and decision-making in the company. Participants opinion differ on how receptive the start-up leaders are when followers challenge the way they do business. There was a clear discrepancy in the way employees and founders viewed and described this aspect of leadership. While founders suggest that they are open to the ideas and suggestions from all collaborators, employees disagree and give examples of the opposing trend.

\subsection{Big company and Start-up Opposition for Understanding Entrepreneurial Leadership}

Another important theme, which has emerged during the analysis of the patterns and reoccurring themes in the data, is related to the size of the organization. All participants attempted to understand the entrepreneurial leadership by contrasting start-up environment with "big companies" and "large organizations". There is a number of important differences, according to the participants that lead to distinctive leadership behaviour linked to those two environments: Secured setting as opposed to uncertainty - of the start-up environment, the absence of the structure and hierarchy and the distinct potential for developing leadership abilities. Big companies have more opportunities for developing leadership abilities as opposed to start-ups, where natural leadership 
potential of an individual is considered as important factor influencing the leadership in those settings.

\section{$5 \quad$ Discussion and Implications}

\subsection{Entrepreneurial Leadership}

The main objective of the present research is to understand the nature of the leadership in the start-ups. In doing so, the key elements of the entrepreneurial leadership were explored: why the entrepreneurial leadership is important and how it is utilized in the start-ups' settings in order to answer this main research question we have outlined.

The Conceptual framework was based on the entrepreneurial leadership construct proposed by Renko et al., (2013) that suggest 8 distinct elements of the entrepreneurial leadership. Interview questions were framed around those elements, additional elements referenced in the literature have been added such as opportunity recognition and utilization, influencing abilities, being a role model, etc. [6]. The format of the semi-structured interview and open-ended questions gave freedom and flexibility to the participants to define what other elements they consider relevant for the entrepreneurial leadership based on their life experiences. All that gave sufficient qualitative data that can be generalized beyond the 10 start-ups that the interviewees represent.

Overall findings of the present study demonstrate that the entrepreneurial leadership has a significant impact on start-ups. A number of distinctive features such as vision, passion, risk, innovation, and creativity have been emphasized by the small sample of the study participant entrepreneurs. Although the elements listed here have been already discussed by a number of authors [8], [15] in relations with the entrepreneurial leadership, the previous studies have mostly used the quantitative tools to study the construct that limited the understanding of how and why these elements occur in certain settings. The present study, on the other hand, gathered rich contextual data outlining details on the context and factors that surround each element, analyzing reasons for the occurrence of each element in a particular entrepreneurial setting.

\subsection{Entrepreneurial Leadership across the Start-up Life-cycle}

Scholarly work of the recent years has increasingly focused on understanding the entrepreneurial leadership as a process [3]. Leitch and Volery (2017) suggest that entrepreneurial leadership as a social process drawing on the human capital and social capital theory. Freeman et al. (2015) view entrepreneurial leadership in the context of the start-up growth outlining key challenges that entrepreneurial leaders need to overcome in the process of the start-up development and suggesting that the adequate capabilities of the leaders strategic thinking, coaching, and self-evaluation [13]. Another academic paper that pioneered linking the leadership and start-up development in the scholarly research has been produced by Swiercz and Lydon (2002). The twophase entrepreneurial leadership model explicitly includes the leader as an essential part of the organizational transition and life cycle [3].

Building upon the scholarly work that we have outlined and considering the gap in the research that calls for a better understanding of the leadership processes in various 
contacts across the time present paper has adopted the four-stage S-curve model developed by Overall and Wise (2015) [14]. The proposed model gives a holistic view of the start-up-lifespan by incorporating the innovation life-cycle, customer development and funding stages of the start-ups as key element influencing each stage.

The findings suggest that the leadership is changing across the lifespan of the startup and distinct conditions and features are characteristic for the entrepreneurial leadership within each respective stage.

\subsection{Entrepreneurial Leadership as a Leader/Follower Co-creation}

Recent academic efforts in the leadership research demonstrate increased scholarly interest in understanding the leadership as a co-creation of the leader and follower. The interest is shifting from the top-down understanding of the leadership to the flat leadership construct. In line with these developments the concepts of the shared [22] and distributed [23] leadership emerged, that attempt to capture the nature of leadership in contrast with the top-down leadership approach focuses more on abolishing hierarchies in leadership enactment and gives space for various actors in the organization to act as a leader in diverse conditions. Scholars have noted that the shared and distributed leadership have been theoretically conceptualized while still lack the evidence [22]. Studies that have previously analyzed the shared leadership in the new ventures suggested that shared leadership has a positive impact on the team performance in the new ventures [24].

Start-up with the flat hierarchical structure is a perfect environment where shared and distributed leadership patterns could be traced. Thus, it was not surprising that the elements and themes related to the shared/distributed leadership and leader/follower relationship dynamics have emerged from the findings presented here. Firstly, the finding demonstrates the interdependence of the actors. All actors are equally important for the success if any of those fail, start-up risk for the major failure. The finding also acknowledges the significance of the teams for the start-up work. All participants have highlighted developing the team as an essential condition for the start-up success.

Findings related to the leadership in four stages of the start-up lifecycle give additional specificities on the topic, suggesting that the development and growth of the team, sourcing the relevant people, sharing and delegating responsibilities and assigning the right roles to the team member are critical during the 3 rd and 4th stages of the start-up development. In addition to this, findings suggest a more important role and contribution of followers in the leadership co-creation. While the entrepreneurial leadership theory, along with other mainstream leadership theories focuses largely on the leader and understands leadership mainly from leaders perspective, the present research has attempted to show both leader and follower perspective for understanding the entrepreneurial leadership in start-ups. The recent study targeted both the follower and leader for generating respective data and gave both accounts in the findings of the study. 


\subsection{Contextual Factors Defining Leadership in Start-ups}

An important gap in the literature on the entrepreneurial leadership has been related to the limited understanding of the context where the entrepreneurial leadership occurs and factors that influence the phenomenon in various environments [15], [16].

Ireland et al. (2003) have discussed the opposition of the big company and start-ups with regards to leadership. Researchers suggested that in large organizations entrepreneurial leadership is mostly concerned with collecting the right resources and is considered to be a foundation for the strategic decision-making. In contrast to the new ventures, entrepreneurial leadership is connected to developing innovative approaches for solving the problems of the customers [15].

The findings presented in this research reveal that the contrasting settings of the startups and big organizations appear to be important influencing factors for developing the entrepreneurial leadership in a particular setting. More specifically, the findings suggest the following influencing factors: secured setting as opposed to uncertainty, absence of the structure and hierarchy, and leaders development track as the key conditions shaping leadership in those environments. Relevant examples and individual experiences of the entrepreneurs participating in the research have been analyzed.

\section{Conclusion}

In summery we can point out that the mainstream leadership research does not allow full understanding of the leadership processes in the start-ups at different stages of its development. We suggest that the entrepreneurial leadership theory is a more relevant construct for understanding and capturing the complex processes in a highly volatile environment. We believe that the present paper deepens the scholarly knowledge on the nature of the entrepreneurial leadership by investigating entrepreneurial leadership in the start-ups setting, including through the perspectives of the leader and follower in constructing the concept and capturing the entrepreneurial leadership process across the lifecycle of the start-ups.

\section{$7 \quad$ References}

1. Statista - The Statistics Portal for Market Data, Market Research and Market Studies, https://www.statista.com/

2. Swiercz, P., Lydon, S.: Entrepreneurial leadership in high-tech firms: a field study. Leadership \& Organization Development Journal. 23, 380-389 (2002)

3. Leitch, C., Volery, T.: Entrepreneurial leadership: Insights and directions. International Small Business Journal. 35, 147-156 (2017)

4. Schumpeter, J., Schumpeter, E.: History of economic analysis. Routledge, London (1997)

5. Cunningham, J., Lischeron, J.: Entrepreneurship: Some Popular Impressions and New Information. Journal of Small Business \& Entrepreneurship. 10, 46-50 (1993)

6. Renko, M., El Tarabishy, A., Carsrud, A., Brännback, M.: Understanding and Measuring Entrepreneurial Leadership Style. Journal of Small Business Management. 53, 54-74 (2013)

7. Cai, W., Lysova, E., Khapova, S., Bossink, B.: Does Entrepreneurial Leadership Foster Creativity Among Employees and Teams? The Mediating Role of Creative Efficacy Beliefs. Journal of Business and Psychology. (2018) 
8. Gupta, V., MacMillan, I., Surie, G.: Entrepreneurial leadership: developing and measuring a cross-cultural construct. Journal of Business Venturing. 19, 241-260 (2004)

9. Zaech, S., Baldegger, U.: Leadership in start-ups. International Small Business Journal. 35, 157-177 (2017)

10. Denti, L., Hemlin, S.: Leadership and Innovation in Organisations: a Systematic Review of Factors That Mediate or Moderate the Relationship. International Journal of Innovation Management. 16, 1240007 (2012)

11. Huang, S., Ding, D., Chen, Z.: Entrepreneurial Leadership and Performance in Chinese New Ventures: A Moderated Mediation Model of Exploratory Innovation, Exploitative Innovation and Environmental Dynamism. Creativity and Innovation Management. 23, 453-471 (2014)

12. Swiercz, P., Lydon, S.: Entrepreneurial leadership in high-tech firms: a field study. Leadership \& Organization Development Journal. 23, 380-389 (2002)

13. Freeman, D., Siegfried, R.: Entrepreneurial Leadership in the Context of Company Start-Up and Growth. Journal of Leadership Studies. 8, 35-39 (2015)

14. Overall, J., Wise, S.: An S-Curve Model of the Start-Up Life Cycle Through the Lens of Customer Development. The Journal of Private Equity. 150213200538007 (2015)

15. Ireland, R., Hitt, M., Sirmon, D.: A Model of Strategic Entrepreneurship: The Construct and its Dimensions. Journal of Management. 29, 963-989 (2003)

16. Harrison, C., Paul, S., Burnard, K.: Entrepreneurial leadership in retail pharmacy: developing economy perspective. Journal of Workplace Learning. 28, 150-167 (2016)

17. Bryman, A., Bell, E.: Business Research methods. Oxford University Press, Oxford (2015)

18. Corbin, J., Strauss, A.: Grounded Theory Research: Procedures, Canons and Evaluative Criteria. Zeitschrift für Soziologie. 19, (1990)

19. Kempster, S., Parry, K.: Grounded theory and leadership research: A critical realist perspective. The Leadership Quarterly. 22, 106-120 (2011)

20. Punch, K.: Introduction to social research. Sage, Los Angeles (2014)

21. Saldaña, J.: The coding manual for qualitative researchers. SAGE (2009)

22. Ensley, M., Hmieleski, K., Pearce, C.: The importance of vertical and shared leadership within new venture top management teams: Implications for the performance of startups. The Leadership Quarterly. 17, 217-231 (2006)

23. Gronn, P.: Distributed leadership as a unit of analysis. The Leadership Quarterly. 13, 423$451(2002)$

24. Shamir, B., Lapidot, Y.: Trust in Organizational Superiors: Systemic and Collective Considerations. Organization Studies. 24, 463-491 (2003) 